\title{
¿Cómo mueren las democracias en América Latina? Desafíos y estrategias para la redemocratización y el cumplimiento del Estado de Derecho ${ }^{1}$
}

\author{
How democracies die in Latin America? Challenges and strategies \\ for redemocratization and compliance with the Rule of Law
}

Janeth Hernández Flores

División de Ciencias Sociales y Humanidades Universidad Autónoma Metropolitana, Unidad Cuajimalpa, México ORCID iD: https://orcid.org/0000-0001-9584-3497

E-mail: jhernandezf@cua.uam.mx

Resumen: Hace poco tiempo Levistsky preguntaba: ¿cómo mueren las democracias? En su disertación señala que anteriormente las democracias morían en manos de militares y regímenes dictatoriales, pero al día de hoy colapsan de manera más sutil. De aquí surgen las siguientes incógnitas: ¿cómo mueren las democracias en Latinoamérica?; ¿cuáles son los factores que permiten determinar que la democracia está colapsando en la región?; ¿cómo puede el derecho contribuir a que sobrevivan las democracias? Tomando como base estos interrogantes, en la presente investigación se reflexiona - a partir de algunas categorías analíticas de los estudios críticos-, sobre cuáles son los principales desafíos existenciales de la democracia y cómo se articula una estrategia jurídica que trate de restringir los avances antidemocráticos en la región. Se propone una serie de acciones para lograr la redemocratización de los países latinoamericanos y, por ende, que se cumpla el paradigma del Estado Democrático de Derecho. Hoy en día, la arbitrariedad persiste en la región bajo sofisticadas y encriptadas formas antidemocráticas, por ello, es importante revelar y contrarrestar esas corrientes que atentan contra los avances democráticos y los postulados de protección de la dignidad de las personas: los derechos humanos.

${ }^{1}$ Agradezco el financiamiento del Consejo Nacional de Ciencia y Tecnología (CONACYT-México) / Universidad Autónoma Metropolitana. 
Palabras clave: democracia, Estado de Derecho, redemocratización, teoría crítica, derechos humanos

\begin{abstract}
Levistsky recently asked: ¿How democracies die? In his dissertation, he points out that democracies used to die at the hands of military and dictatorial regimes, but today the tactics for their decline have transmuted: they collapse in a more "subtle" way. Hence the following questions arises: ¿How democracies die in Latin America? What are the factors that determine that democracy is collapsing in the region? How can the law help democracies "survive"? Based on these questions, this research reflects - considering some analytical categories of critical studies-, on what are the main "existential challenges" of democracy and how it is articulated a legal strategy that attempts to restrict antidemocratic advances in the región. An alternative is proposed to achieve the redemocratization of Latin American countries and, therefore, the paradigm of the Democratic Rule of Law is fulfilled. Currently, arbitrariness persists in the region under sophisticated and encrypted anti-democratic forms, therefore it is important to reveal and counteract those currents that threaten democratic advances and the postulates of protection of people's dignity: human rights.
\end{abstract}

Keywords: democracy, Rule of Law, redemocratization, critical theory, human rights

\title{
INTRODUCCIÓN
}

Los desafíos sobre la transición y consolidación democrática después de los regímenes militares y dictatoriales son constantes en la historia de América Latina. Actualmente, las democracias mueren en manos de gobiernos de civiles, elegidos mediante el voto, que utilizan las instituciones democráticas para minar la democracia o subvertirla (Levistsky, 2019). Así, mediante el ardid electoral e institucional se ocultan figuras y gobiernos autoritarios que realizan acciones antidemocráticas. Estos regímenes cooptan gran número de militantes y seguidores; ese apoyo político lo utilizan para realizar acciones arbitrarias de dominación y control.

Las instituciones democráticas en Latinoamérica son acechadas por conductas ilegales, posturas ideológicas radicales, doctrinas religiosas e intereses de diversa índole. De esta forma, tras una fachada democrática, los mandatarios con instintos autoritarios hacen uso de elecciones, plebiscitos, reformas constitucionales y fallos judiciales para perpetuar su mandato y así concentrar el poder del Estado. Pero, además, utilizan la violencia, en sus distintas modalidades, para disciplinar y controlar a las voces contestatarias, a los disidentes y a la oposición política que exigen condiciones democráticas reales.

El trayecto latinoamericano hacia la redemocratización ha sido difícil por los cambios sociales y políticos constantes en la región, que amenazan los avances democráticos que habían experimentado muchos países latinoamericanos (Pettiná \& Rojas, 2020). Pero en los últimos años, una serie de graves tensiones 
sociales y hechos violentos en varios países de la zona, hacen resurgir con más fuerza la idea de que la democracia está expirando.

Naciones Unidas señala que la democracia está estrechamente vinculada al Estado de Derecho y al ejercicio de los derechos humanos (Altamirano Dimas, 2017). Al día de hoy, es difícil sostener que puedan hacerse efectivos los derechos humanos sin la democracia y el Estado de Derecho. La democracia no tiene parangón con otro régimen político que garantice las prerrogativas esenciales que protegen la dignidad de las personas.

En este contexto, recurrir a la teoría crítica para lograr reducir tales efectos antidemocráticos es útil. El pensamiento crítico ofrece una amplia gama de cuestionamientos anti-sistémicos que deben ser reflexionados, debatidos y, en su caso, asimilados desde la perspectiva positivista tradicional. Constituye una fuente imprescindible para fomentar la autocrítica, superar tópicos trillados y comprender de manera integral los conflictos que han permanecido eclipsados por las metodologías tradicionales.

En consecuencia, a partir de ciertas categorías de análisis del pensamiento crítico, esta investigación examina cómo ciertas acciones y actos de violencia que pasan inadvertidos y parecen ininteligibles —al verlos en forma aislada o desarticulada - , han transformado el entorno social y representan desafíos letales para las instituciones democráticas latinoamericanas, principalmente en el periodo 2016-2020. En sus apartados, se trata de responder la triada de preguntas planteadas de manera preliminar y presentar acciones que permitan hacer operativo al Estado de Derecho y seguir erigiendo a la democracia como fórmula inequívoca que garantice las ideas de libertad y las prerrogativas esenciales de los seres humanos.

\section{ESTADO DEL ARTE}

El debate teórico sobre la calidad, el sostenimiento y la crisis del régimen democrático no es nuevo. En distintas regiones del orbe, incluyendo América Latina, se han decantado por reflexionar acerca de la "muerte de la democracia" (Keane, citado por Woldenberg, 2018). También ideas análogas han sido desarrolladas en distintas versiones: "quiebra de la democracia" (Allub, 1980; Degregori \& Rivera, 1993; Linz, 1996), "colapso de la democracia" (Moss, 1977), "crisis democrática" (Cibrian, 1978; Puerta Riera, 2016; Taylor, 2019), entre otras.

Históricamente, Degregori y Rivera (1993), enfatizan el papel de las Fuerzas Armadas luego de la transición democrática en el Perú -1978-80-, que 
estuvieron ligadas al problema de la violencia política, por lo que los gobiernos civiles incurrieron en una "abdicación de la autoridad democrática". Por su parte, Moss (1977) examina qué hacer en un sistema democrático colapsado y dominado por minorías extremistas ante situaciones límites provocadas por fenómenos sociales como la inflación, el paro o por infiltraciones de grupúsculos ideológicamente antidemocráticos. Fraser (2012) asegura que la crisis es vista no solo en relación con la democracia sino como una crisis más generalizada que implica otras facetas: crisis ecológica, crisis financiera, crisis de reproducción social. En su estudio Taylor (2019) delibera sobre las diversas formas de deterioro democrático, como el aumento de la desigualdad, la xenofobia y la polarización, así como las posibles formas de salir de la crisis.

Desde otra perspectiva, los estudios tradicionales cuantitativos examinan variables, indicadores y datos estadísticos que miden factores que inciden en la pérdida de calidad de un régimen democrático; entre otros, la cultura política y la confianza en instituciones (Brown, 2018). Gwangeun (2016), por ejemplo, mide el desempeño democrático a través del Democratic Performance Index (DP) que contiene ocho dimensiones centrales: libertades individuales, Estado de Derecho, esfera pública, transparencia, participación, representación, competencia y mutuas restricciones. Estos cálculos no permiten reflexionar cualitativamente sobre cuestiones no evidentes que subyacen en las nuevas formas dinámicas, contingentes y disruptivas que atentan contra los regímenes democráticos.

Todas las expresiones de decepción democrática — democracia arbitraria (Molina, 2010), democracia desfigurada (Urbinati, 2014), etc.—, coinciden en la necesidad de reinventarse para evitar ser sustituida o desplazada por opciones que descartan los propios valores democráticos. En un intento por rescatar el espíritu de la democracia se ha tratado de redefinir la democracia a través de nociones como: postdemocracia, cosmocracia, democracia postliberal, democracia multidimensional y contrademocracia (Puerta Riera, 2016).

Ahora bien, Roca Jusmet (2019), retomando a Žižek, alude críticamente que la democracia liberal se deteriora al prever un sujeto vacío, un sujeto de derechos sin atributos, universal, que no atiende a las particularidades y a los valores éticos de las personas. Sustancialmente, el pensamiento crítico es un método, analítico y auto-reflexivo, teóricamente sustentado, de crítica de ideologías y prácticas convencionales, incluyendo los sistemas políticos. En el núcleo del pensamiento crítico está la necesidad de construir futuros alternativos y mejores (Cebotarev, 2003). 


\section{CONTEXTo DEMOCRÁTICO EN LA REGIÓN LATINOAMERICANA}

Después de periodos de inestabilidad política, superando la existencia de gobiernos militares y dictatoriales, América Latina comenzó el proceso de transición democrática en las postrimerías del siglo pasado. Esta causa fue asistida por una justicia transicional cuyos objetivos, entre otros, fueron crear instituciones y respetar el Estado de Derecho (ICTJ, s.f.). A principios de siglo, se auguraban mejores tiempos para los procesos democráticos. Malloch Brown (2004), Administrador del Programa de Naciones Unidas para el Desarrollo -PNUD-, mostraba gran orgullo por las más de dos décadas de gobiernos democráticos en Latinoamérica. A la vez también asentía que se mantenían profundas desigualdades, pobreza y aseguraba que había aumentado la insatisfacción ciudadana con la democracia, generando en algunos casos consecuencias desestabilizadoras.

En la actualidad, según Bonometti y Ruiz (2010), la democracia en América Latina presenta elementos de debilidad relacionados con la incapacidad del Estado de extender los derechos humanos a toda la población, requisito para garantizar la cohesión social y el apoyo a la democracia como elemento legitimador. Sin embargo, las conductas antidemocráticas no son del todo evidentes, muchas son invisibilizadas o eclipsadas por otros fenómenos políticos, sociales o económicos, por ejemplo, los poderes facticos: empresas transnacionales, crimen organizado, narcotráfico, grupos paramilitares u organizaciones religiosas. Todos ellos se disputan el control social y diversos intereses, principalmente económicos. Por consiguiente, las expectativas sobre la democracia se traducen, entre otros, en Argentina, grave crisis financiera; en Brasil; extremismo conservador; en Bolivia, crisis política y social, golpe de Estado suave; en Chile, fuerte inestabilidad social y política; en Colombia, crisis social y violencia exacerbada hacia líderes sociales; en Costa Rica, democracia plena; en Cuba, reformismo post Castro; en Ecuador, crisis social y conservadurismo; en El Salvador, violencia y crimen; en Guatemala, migración irregular creciente; en Honduras, violencia y migración; en México, violencia y narcotráfico; en Nicaragua, autoritarismo; en Panamá, reformismo; en Paraguay, inestabilidad política; en Perú, corrupción; en Puerto Rico, crisis de gobernabilidad; en República Dominicana, recuperación económica; en Uruguay, corrupción; y, finalmente, en Venezuela, autoritarismo (Martínez Vara, 2019).

En tales términos, no es extraño el desencanto democrático. Según datos del Latinobarómetro 2018, el apoyo a la democracia no llega a la mitad de la ciudadanía del continente con un $48 \%$ de aprobación (Rivas Molina, 2018). El 
dato desagregado por países confirma la anuencia democrática de Argentina, Uruguay y Costa Rica. Las naciones más pobladas del continente, Brasil y México, se mueven en el amplio espectro del desencanto (Galindo, 2019). En este sentido, Cristi y Tranjan aducen: "sociedades como Brasil y Chile nos fuerzan a entender que el desarrollo democrático puede ser lento y doloroso...Nuestras sociedades deben continuamente pensar y repensar, teórica y prácticamente, maneras de desarrollar formas políticas que aproximen el ideal democrático republicano a nuestra realidad contingente" (Cristi \& Tranjan, 2010, p. 615).

En los últimos tiempos no se ha tenido cuidado con trasgredir los parámetros democráticos; éstos son un modelo primigenio que irradia valores en todos los ámbitos de la vida pública. Al respecto, Brown (2018) señala que, en la democracia de manera amplia, como régimen, se valoran instituciones representativas que por su naturaleza y diseño deben ser abiertas, plurales e incluyentes, pero también debe existir la capacidad del Estado para responder de manera pronta ante problemas emergentes y no triviales.

\section{MECANISMOS ANTIDEMOCRÁTICOS ACTUALES: ¿CUÁLES SON LOS FACTORES QUE PERMITEN DETERMINAR QUE LA DEMOCRACIA ESTÁ COLAPSANDO EN LA AMÉRICA LATINA?}

En el mundo se habla de la crisis democrática, pero en el caso de Latinoamérica se pueden detectar ciertos factores antidemocráticos disímiles a los que ocurren en otras latitudes. Existen muchas aristas específicas de la región que no son asimilables ni comparables con las que suceden en democracias "consolidadas" en países desarrollados.

Una cuestión muy importante que indica Levistsky (2019), común en la región latinoamericana, es el alto grado de polarización entre la sociedad que puede matar a la democracia. Aunque las disputas no se basan únicamente en la pertenencia en uno $u$ otro partido, también se fundan en cuestiones más profundas; resultan ser síntomas o la expresión de transformaciones que tienen lugar en las sociedades que ven emerger identidades sociales, raciales, culturales y, muchas veces, posturas ideológicas. Por ejemplo, Cruz Olmeda (2019) subraya que en Brasil la polarización en el escenario político de los seguidores del Partido de los Trabajadores -PT-y los anti-PT, facilitó el ascenso de Jair Bolsonaro porque generó terreno fértil para su discurso ideológico, que retrataba al PT como el responsable de introducir la doctrina marxista, una doctrina a la que se acusaba de 
ser contraria al sentir nacional, impuesta desde el exterior y una amenaza para los valores tradicionales de los brasileños.

En la mayoría de países latinoamericanos sucede que los partidos representan distintas comunidades e identidades, por ejemplo: Bolivia, El Movimiento al Socialismo -MAS-/Frente de Unidad Nacional -UN-; México, Movimiento de Regeneración Nacional -MORENA-/ Partido Acción Nacional PAN-; Brasil, Partido Social Liberal -PSL-/Partido de los Trabajadores -PT-.

El otro es altamente peligroso para el estrato económico, el grupo racial o étnico, para las costumbres o la religión del adversario. En ese entorno, ante la tesitura de perder el poder, el control es profundamente amenazante, provoca crisis existenciales a gran número de personas. En respuesta a ese estrés e inseguridad, los ciudadanos están más dispuestos a tolerar el comportamiento abusivo y antidemocrático de parte de gobierno de su partido. Perciben que el triunfo del otro partido es algo catastrófico, intolerable; así se comienza a justificar el uso de medidas extraordinarias y arbitrarias. (Levistsky, 2019)

En Brasil se ha calificado de antihumano al presidente Bolsonaro, por oponerse a decretar el aislamiento social para evitar la propagación del virus SARS-CoV-2, pese a que aquel país está "desprovisto de un sistema de salud, donde la atención médica universal, gratuita y accesible para toda la población es apenas mera utopía”. (Leznova, 2020, p. 41). ${ }^{2}$ En Venezuela, en 2016, el presidente Maduro fue blanco de severas críticas por parte de la oposición, al extender por dos meses más el Decreto de Estado de excepción y emergencia económica, que fue avalado por el Tribunal Supremo, y que señala, entre otras atribuciones, que el mandatario puede disponer de recursos sin control del Parlamento. Además de esto, el Decreto indica que el gobierno podrá aplicar sanciones de carácter político contra los representantes de poderes públicos que obstaculicen la continuidad de la aplicación de la medida. (Guti, 2016). En Colombia, se le ha acusado al presidente Duque de concentrar el poder y ser arbitrario. En el primer caso, su absolutismo surge de tres factores: a) la erosión de la autonomía de otros poderes del Estado, al gozar de su incondicionalidad; b) tratar de consolidar mayorías estables en el Congreso, a través, entre otras, a la mermelada que tanto crítico del gobierno pasado; c) los riesgos y temores ocasionados por la pandemia de COVID-19, en donde el presidente utilizó intensamente los poderes de excepción.

\footnotetext{
${ }^{2}$ Akerman et al. (2020) precisan que el Sistema Único de Salud (SUS) en Brasil es fuente de orgullo para los sanitaristas brasileños por sus principios basados en la universalidad, equidad e integralidad; no obstante, su consolidación no llegó a darse por el desmantelamiento que sufrió en el contexto de políticas neoliberales.
} 
(Uprymny Yepes, 2020). En segundo lugar, fue calificado de arbitrario al instruir el despliegue operacional de la fuerza pública para desbloquear las vías que permanecían obstaculizadas en el marco del paro nacional que inicio el 28 de abril de 2021, contra medidas tributarias, que culminaron con al menos 50 personas muertas a manos de efectivos de la fuerza pública, 600 personas heridas, de las cuales al menos 37 sufrieron lesiones oculares por disparos hechos por la policía, la detención arbitraria de 430 personas, violencia sexual contra 21 mujeres y se reportaron 520 personas desparecidas (Sputnik, 2021).

Ahora bien, existen otras causas de insatisfacción y frustración social atribuidas a algunos regímenes democráticos en América Latina. Para exponer estas causas se utilizará una importante herramienta conceptual desarrollada por Foucault: el dispositivo, entendido como la red y el vínculo que puede establecerse entre elementos heterogéneos que tienen una "función estratégica dominante" (1983). Para Agamben, el dispositivo es "cualquier cosa que tenga de algún modo la capacidad de capturar, orientar, interceptar, modelar, controlar y asegurar los gestos, las conductas, las opiniones y los discursos de los seres vivientes" (2009). Por su parte Deleuze explica que el dispositivo es una "máquina de hacer ver y hacer hablar que funciona acoplada a determinados regímenes históricos de enunciación y visibilidad" (1990).

El uso del dispositivo al que se denomina antidemocrático permite decodificar cómo se articulan los procesos y relaciones que amenazan la viabilidad democrática y los derechos humanos en su conjunto. El dispositivo antidemocrático está compuesto por prácticas estratégicas que se definen por la regularidad y la racionalidad (Foucault, 1998). De acuerdo con lo expuesto, el dispositivo antidemocrático se compone de varios elementos.

\section{a) El alto nivel de desigualdad}

En todo el mundo, gran número de ciudadanos sufren la exclusión sistemática (Cristi \& Tranjan, 2010). América Latina no es la excepción y adolece de pobreza y desigualdad multidimensional. A la escasez económica se agregan la falta de acceso a las necesidades y a los servicios básicos, la exclusión social y la discriminación que afectan a diversos grupos sociales - pobres, indígenas, campesinos, mujeres, etc. - creando una gran masa de excluidos. La desigualdad impide la creación y consolidación de una base social amplia capaz de sustentar el desarrollo de democracias sólidas y efectivas. (Bonometti \& Ruiz, 2010) 
El proceso democrático debe ocuparse de la redistribución de la riqueza, para darle a todas las personas los recursos económicos materiales que les permitan ejercer todos sus derechos al desarrollo sostenible. El índice de Gini mide la desigualdad con base a dos variables absolutas, en donde 0 representa una equidad perfecta, mientras que un índice de 100 representa una inequidad perfecta. Conforme a los últimos datos del Banco Mundial los países latinoamericanos con más desigualdad fueron: Brasil 53,3 -2017-Honduras 50,5 -2017-; Panamá 49,9 -2017-; Colombia 49,7 -2017-; México 48,3 - 2016-; Costa Rica 48,3 -2017-; Guatemala 48,3 -2014-; Paraguay 47,9 -2016-; Chile 46,6 -2017-; Nicaragua 46,2 -2014-; República Dominicana 45,7 -2016-; Ecuador 44,7-2017-; Bolivia 44,0 -2017-; Perú 43,3 -2017-; Argentina 41,2 -2017-; Haití 41,1 -2012-; Uruguay 39,5 -2017-; El Salvador 38,0 -2017- (Banco Mundial, s.f.). En este contexto y tomando en consideración el programa Horizontes CEPAL, Laís Abramo, Directora de la División de Desarrollo Social la Comisión Económica para América Latina -CEPAL-, afirma que América Latina sigue siendo la región más desigual del mundo (CEPAL, 2017). Con estos altos grados de desigualdad, los proyectos de mejoras democráticas deben poner énfasis en las asimetrías económicas y sociales que permean la región.

\section{b) Transición en donde un grupo étnico dominante pierde su mayoría}

Si bien este elemento no es visible en América Latina, donde hay una profusa mezcla étnica y grandes poblaciones de pueblos originarios, en general, los grupos indígenas están subrepresentados. En la región el sistema sociocultural los excluye por su apariencia y fenotipo, al considerarlos como sinónimo de atraso, inferioridad y falta de cultura. La estructura discriminatoria se refleja en la esfera política, donde existe una clara subrepresentación en los espacios de toma de decisiones (Martínez Espinoza, 2015).

Un caso especial es Bolivia, país donde casi la mitad de la población es de origen indígena y en donde el ex presidente de izquierda Evo Morales, de origen Aimara, llegó y permaneció en el poder por más de trece años con amplio apoyo de los grupos indígenas. Con la renuncia de Evo Morales, en medio de una profunda crisis política en noviembre de 2019 y de acusaciones de golpe de Estado suave (Corrales, 2019), la causa indígena que asumió y representó parecía que terminaba. Al llegar Jeanine Añez a la presidencia interina parecía una nueva era en lo que a símbolos se refiere. Por ejemplo, juró su cargo sobre una Biblia 
para aludir el supuesto retorno de la religión al Gobierno boliviano. Morales retiró esos símbolos religiosos de los actos cuando la Constitución de 2009 aprobó que el país era laico, y a cambio, introdujo otros como la whipala, la bandera de los pueblos indígenas andinos, en los eventos oficiales (Aliaga, 2020). Con la jornada electoral del 18 de octubre de 2020, se decidió seguir una continuidad política a cargo del ahora presidente Luis Arce.

Cabe señalar que en varios países, indica Brown (2018), la transición democrática se utilizó como discurso y coartada política para legitimar regímenes que, en lo fundamental, mantuvieron viejas prácticas autoritarias: el corporativismo, la compra de votos, el acarreo de electores, la maquila de pobres como estrategia de Estado para garantizar clientelas estables, la profunda división entre clases, así como prácticas discriminatorias contrarias a la dignidad humana, persistencia de desigualdades ancestrales inadmisibles, colusión entre políticos y empresarios corruptos $\mathrm{y}$, un largo etcétera de prácticas no superadas, algunas de ellas coloniales, que ponen en cuestión la efectividad de la democracia.

\section{c) Elección de un presidente con instintos autoritarios o populistas}

En América Latina es común la interferencia del poder ejecutivo en el poder judicial, pese a reformas constitucionales para aumentar su independencia. La concentración de poder en el ejecutivo pone en peligro la división de poderes (Bonometti \& Ruiz, 2010). El poder político que ejerce el ejecutivo, indica Walzer (2004), por lo general, es fundador y transgresor de normas pues confiere la posibilidad de hacer más severos o flexibles los criterios distributivos, o intervenir o restringir el acceso a otras esferas distributivas.

Una de las causas del autoritarismo, en algunos países como México, es que, durante mucho tiempo, el dominio de un solo partido político a nivel federal significó un poder excesivo del ejecutivo que se normalizó. El régimen de partido hegemónico por más de 80 años escondió represión, falta de libertades, arbitrariedad de las decisiones gubernamentales, colusión de las autoridades, corrupción desmedida, improvisación interminable y demagogia en exceso (Brown, 2018).

En América Latina, el autoritarismo no es exclusivo de gobiernos de izquierda, de centro o de derecha. Permea en distintos grupos e ideologías. Molina (2010) señala que: "el exceso de poder", constituye una de las nuevas formas más sutiles y ambiguas que enfrentan las libertades. En relación con Bolivia indica lo siguiente: 
[...] hacia fines de 2010 la democracia boliviana...se transformó claramente en una democracia sin reglas o "arbitraria" [...] justificaciones teóricas esconden, bajo un camuflaje democrático, un fondo revolucionario, es decir, autoritario [...] El Partido Movimiento al Socialismo (MAS) [...]comenzó a burlarse de la Constitución y las leyes que aprobó él mismo, trayendo a escena, vestido con todas sus galas, un viejo fantasma que Bolivia ha tratado de conjurar a lo largo de toda su vida: el despotismo de los poderosos (Molina, 2010, p. 14).

En Brasil, señala Pirotta (2019), el presidente Jair Bolsonaro ha sido acusado de autoritario, entre otras, por: a) la Agencia Nacional del Cine, decidió dejar de financiar películas que aborden la temática LGBT y otras por ser consideradas inmorales; b) el ministro de Educación anunció recortes a las universidades que organizan "balbúrdia" -lío, desorden-, en referencia a actividades extracurriculares de contenido cultural y político; c) los nuevos avances en la causa que investiga a uno de sus hijos, Flavio, por nexos con las milicias de Río de Janeiro, impulsaron al gobierno a ensayar una intervención en diferentes instituciones como la cúpula de la Policía Federal, encargada de llevar adelante las investigaciones, así como el COAF o Consejo de Administración Financiera, que detectó las irregularidades de Flavio Bolsonaro. Este periodista, acota:

El autoritarismo del líder ultraderechista Jair Bolsonaro [...] ha alcanzado en los últimos días cotas difícilmente superables. Aun conociendo su admiración por el régimen militar instaurado desde 1964 hasta 1985, su última actuación al respecto ha dejado perpleja a buena parte de la población al denigrar en un discurso la memoria de uno de los asesinados por la dictadura. (Pirotta, 2019)

Sin embargo, no se puede negar que un amplio sector de la población apoya al Ejecutivo brasileño. La explicación a esta tendencia, señalan Moura de Oliveira y Veríssimo Veronese (2019), son los “problemas que nunca resolvieron los brasileños" que se traducen en la incapacidad de constituirse como una nación igualitaria, con sentimiento de colectividad, paz social y solidaridad. Entre estos problemas históricos no resueltos se encuentran: a) esclavitud y racismo; b) opresión patriarcal y homofobia; c) los derivados de la dictadura militar del siglo pasado; y d) lucha de clases histórica en el país. Esto ha generado: a) permanencia del racismo que también es institucional; b) machismo y homofobia que también son institucionales; c) justificación de la noción que hay una violencia justa siempre y cuando sea por el bien de la nación; y d) prejuicio clasista y cultural. A ello ha de sumarse que con el proceso de democratización sectores hasta entonces marginados comenzaron a adquirir el reconocimiento de sus derechos y generaron una reacción negativa de las capas medias de la sociedad brasileña, quienes se creyeron perjudicadas por esos cambios culturales, políticos y de comportamiento. Precisan, Moura de Oliveira y Veríssimo Veronese (2019), que todas esas 
problemáticas ayudan a entender el odio y el resentimiento que unieron a casi la mitad de los electores en torno a Jair Bolsonaro.

En Chile, una serie de manifestaciones y disturbios originados en Santiago - por el alza en los precios en el sistema público de transporte- y propagados a todas las regiones de Chile, durante los meses de octubre a diciembre de 2019, desembocó en una grave crisis política y social donde la actitud del ejecutivo federal chileno fue calificada como autoritaria: "El Presidente Sebastián Piñera y sus ministros [...] optaron, ante la masiva y extendida manifestación social, por declarar en amplias zonas del país el Estado de emergencia, sacar al ejército a la calle, imponer el toque de queda, suspender derechos civiles e instalar un tono discursivo de violencia, guerra, vandalismo y represión" (Gobierno autoritario y sin respuestas reales, 2019). La respuesta gubernamental fue tan represiva que, al margen de los disturbios y la violencia, hubo muertos y se estiman que al menos 220 personas sufrieron lesiones oculares causadas por balas de goma (Por qué tantos manifestantes, 2019).

En Ecuador, en octubre de 2019, luego de que el gobernó subió el precio de los combustibles — diésel y gasolina—, se suscitaron once días de movilizaciones, represión y caos. La crisis terminó después de que el gobierno derogó el decreto que subió el precio de los citados combustibles con el saldo de 7 muertos y cientos de heridos. De la Torre menciona: "Las credenciales democráticas del gobierno de Lenín Moreno se hicieron trizas y su proyecto de restablecer la institucionalidad quedó en entredicho...Luego del fallido proceso de retorno a la democracia, Ecuador enfrenta una vez más el espectro del autoritarismo en sus versiones de izquierda o de extrema derecha" (De la Torre, 2019).

Todas estas conductas abiertamente autoritarias con el objetivo de concentrar el poder han impactado a la incipiente democracia latinoamericana. Otro factor considerado también como un retroceso democrático sin precedentes es el binomio democracia y populismo. Los movimientos populistas, sean de izquierda o de derecha, han sabido articularse en la retórica democrática: hacen creer a los ciudadanos que tienen un mayor nivel de democracia (Márquez, 2019). Los gobiernos populistas, en términos generales, mantienen dos argumentos básicos: a) las élites y fuerzas externas conspiran contra los intereses del pueblo verdadero, y b) como ellos encarnan la voz del pueblo verdadero, nada debe interponerse en su camino. ${ }^{3}$ Block indica que los mandatarios tienden a no respetar el

\footnotetext{
${ }^{3}$ Ortiz (2018) sostiene que, de hecho, las cuatro democracias muy pobladas hasta hace poco habían elegido regímenes populistas: Narendra Modi, en India; Donald Trump, en los Estados Unidos; Joko Widodo, en Indonesia, y Jair Bolsonaro, en Brasil.
} 
Estado de Derecho, rechazan los procesos de negociación política usados por la elites políticas tradicionales, y prefieren tomar decisiones de manera arbitraria (Mizrahi, 2019). Con base en un estudio realizado por Hawkins et al. (2019), en los últimos 20 años los mandatarios latinoamericanos señalados como populistas o algo populistas son: Hugo Chávez, en Venezuela; Nicolás Maduro, también en Venezuela; Evo Morales, en Bolivia; Jair Bolsonaro, en Brasil; Andrés M. López Obrador, en México: y Daniel Ortega, en Nicaragua. Lo anterior no debe interpretarse como que todos estos personajes representen o hubieran representado un peligro inminente para la democracia, pero al menos, se cataloga que utilizan el name and shame; esto es, humillar al otro, al opositor, haciendo que la conversación política se vuelta tóxica, y a la postre, ello afecte progresiva y significativamente la democracia (Mizrahi, 2019).

\section{d) Los altos niveles de violencia y mortalidad}

El grave problema de violencia generalizada y sistemática que sufren las personas en muchos países latinoamericanos insta a reflexionar y generar propuestas basadas en análisis que desde diversas perspectivas aporten a la consolidación de la democracia y la cultura de paz en América Latina. Esta región es considerada una de las más violentas del mundo, como muestra la elevada frecuencia de homicidios y feminicidios (Bonometti \& Ruiz, 2010).

En su balance sobre las tasas de homicidios por país, la organización InSight Crime, 2018, aporta los siguientes datos por cada 100.000 habitantes: Venezuela, 81,4; El Salvador, 51,0; Jamaica, 47,0; Honduras, 40,0; Trinidad y Tobago, 37,5; Belice, 35,9; México, 25,8; Brasil, 25,0; Colombia, 25,0; Guatemala, 22,4; Puerto Rico, 20,0; Costa Rica, 11,7; Uruguay, 11,8; República Dominicana, 10,4; Panamá, 9,6; Perú, 7,8; Bolivia, 6,3; Ecuador, 5,7; Argentina, 5,2; Paraguay, 5,1; y Chile, 2,7 (Dalby \& Carranza, 2019). Mientras que el Observatorio de Igualdad de Género de América Latina y el Caribe reporta información oficial de 15 países de América Latina y el Caribe, la cual muestra que al menos 3.287 mujeres han sido víctimas de feminicidio en 2018. Si a estos se suman los datos de los 10 países de la región que solo registran los feminicidios cometidos a manos de la pareja o ex pareja de la víctima, se puede afirmar que el número de feminicidios para el año 2018 ha sido a lo menos de 3.529 mujeres (Observatorio de Igualdad de Género de América Latina y el Caribe, 2019).

Es importante destacar que en algunos lugares del área en estudio no se puede hablar de violencia, sino de hiperviolencia, que se origina cuando esta se 
expresa a su máxima potencialidad, haciendo alusión a los más grandes miedos, temores y al dolor extremo de los seres humanos.

Para algunos especialistas, el neoliberalismo es considerado como la causa estructural del descontento social y la violencia. Springer (2015) sostiene que la violencia y el neoliberalismo se han entrelazado, por ello es importante comprender las resonancias de la violencia dentro del modelo económico político ortodoxo del neoliberalismo. En este orden de ideas, Cristi y Tranjan (2010) aducen que hay interpretación sesgada y parcial de la sociedad que postula el neoliberalismo contemporáneo. Este modelo tiende a limitar la intervención del Estado en asuntos jurídicos y económicos, y al mismo tiempo, provee una ideología individualista e instrumentaliza y cosifica al ser humano al tener una concepción netamente economicista de la vida social.

\section{e) Impunidad sistemática}

Es uno de los problemas antidemocráticos más serios que enfrentan los países de América Latina. Se caracteriza por la ausencia de castigos ante crímenes como el homicidio doloso o las graves violaciones de derechos humanos. La impotencia y la incapacidad de las instituciones democráticas del Estado para garantizar certeza en torno a la seguridad y el incumplimiento del pacto social, puede provocar acciones de la sociedad para protegerse (Le Clercq et al., 2016).

El Índice Global de Impunidad, con indicadores en materia de seguridad, justicia y derechos humanos, concluye que, América Latina es la región con mayor impunidad del mundo, de los trece países con mayor índice de impunidad en el mundo, nueve son latinoamericanos. México ocupa el cuarto lugar a nivel mundial, con un índice de impunidad de 69,21 puntos y el primer lugar en el continente americano, y le siguen: Perú, 69,04; Venezuela, 67,24; Brasil, 66,72; Colombia, 66,57; Nicaragua, 66,34; Paraguay, 65,38; Honduras, 65.04; y El Salvador, 65,03 (Le Clercq \& Rodríguez Sánchez Lara, 2017).

En México, por ejemplo, nueve de cada diez homicidios dolosos en 2018 quedaron impunes. Este país tiene la tasa de homicidios más alta de entre todos los miembros de la Organización para la Cooperación y Desarrollo Económico OCDE-, con un 24,8 por cada 100.000 habitantes (Nueve de cada 10 homicidios, 2018). En este tenor, Altmann asevera que "la corrupción e impunidad han generado un malestar en las nuevas clases medias, que están enojadas y asustadas en perder su estatus y están desencantadas con la democracia" (2018). Además, el ejercicio de los derechos de ciudadanía —en el ámbito del acceso a la justicia 
y de la posibilidad de obtener un proceso justo- está condicionado por el origen y condición social de la persona. Los grupos clasificados en las categorías más débiles en todos los países de la región, además de las mujeres, son los pobres, los inmigrantes y los indígenas (Bonometti \& Ruiz, 2010). Lo cierto es que la propia impunidad causa falta de certeza y seguridad jurídica, baluartes del Estado de Derecho.

\section{f) Profundos estándares de corrupción}

Según Melguizo, jefe para América Latina del Centro de Desarrollo de la OCDE, "cuatro de cada cinco latinoamericanos piensan que la corrupción está extendida en su Gobierno" (2018). El Barómetro Global de la Corrupción 2019 realizado por Transparencia Internacional, muestra que la mayoría de población cree que la corrupción en Latinoamérica es un problema grave: Perú, 96\%; Colombia, 94\%; Argentina, 93\%; República Dominicana, 93\%; El Salvador, 93\%; Venezuela, 93\%; Honduras, 91\%; Brasil, 90\%; Guatemala, 90\%; México, 90\%; Panamá, 90\%; Chile, $85 \%$; Trinidad y Tobago, $85 \%$; Costa Rica, $82 \%$; Bahamas, $80 \%$; Jamaica, 78\%; Guyana, 59\%; y Barbados, 53\%. Más de la mitad de las personas entrevistadas sostiene que la mayoría o todos los políticos electos y sus funcionarios son corruptos que prefieren sus intereses privados sobre los públicos. El estudio muestra que en América Latina y el Caribe una de cada cinco personas tuvo que pagar un soborno para acceder a algún trámite o servicio (Transparency International, 2019) .

Desde su perspectiva, Jalife (2019) indica que la corrupción es consustancial al modelo neoliberal, donde el dinero se mueve en las cúpulas. La trascendencia de la corrupción en la democracia es que debilita la cohesión social y reduce la posibilidad de construir un pacto social sólido entre la población (Bonometti \& Ruiz, 2010).

\section{g) Debilidad institucional}

Muchos de los casos de violencia e inseguridad en América Latina son propiciados por la fragilidad de las instituciones para garantizar el Estado de Derecho. Estas instituciones no son capaces de sancionar las conductas delictivas, enviando un mensaje a los transgresores de que pueden actuar con total impunidad; ello vinculado la corrupción genera una dinámica de caos, una "atmosfera de anarquía", de "espacios sin gobierno" o "áreas sin ley". Oppenheimer (2003), citando al General James T. Hill, jefe del Comando Sur de las Fuerzas Armadas 
de Estados Unidos, indica que al día de hoy uno de los principales peligros para la seguridad de América latina no son los ejércitos extranjeros o guerrillas urbanas que toman las capitales y pasan luego a controlar el interior. El peligro viene de organizaciones criminales que ocupan espacios vacíos en las junglas y otros lugares remotos, y se expanden desde aquellos lugares. Entre muchas otras, las áreas sin ley, en América latina son: la Triple Frontera, entre la Argentina, Paraguay y Brasil; el corredor de Tabatinga-Leticia, en la frontera de Brasil con Colombia; la zona de Lago Agrio, entre Ecuador y Colombia, y la selva del Darién, en Panamá.

La democracia es un régimen que admite tensiones entre diversos grupos y corrientes (Innerarity, 2011), pero la fortaleza de las instituciones equilibra las veleidades políticas y sociales, garantizando libertades o asignando responsabilidades a quienes atentan contra los "códigos democráticos" a través de conductas antijurídicas.

h) Grupos de poder: institucional, no institucional, transnacionales, agentes híperviolentos y empoderados económicamente

Wolin (2004) considera que el problema de la democracia es que sucumbe a las redes corporativas en sectores organizados que representan los intereses de grupos que son protegidos por encima del pueblo.

De hecho, sostienen Bonometti y Ruiz (2010), la concentración de la riqueza y del poder implica el uso de instrumentos que permiten a los grupos privilegiados reproducir el statu quo. Esos instrumentos están representados principalmente por la violencia y la corrupción, fenómenos que alcanzan niveles elevadísimos en la región. Al mismo tiempo se produce una cierta interferencia de los poderes fácticos sobre los institucionales, lo que condiciona la capacidad de los gobiernos para dar respuesta a la ciudadanía.

Esto tiene una cierta lógica, explica Walzer (2004), ya que la dominación es consecuencia del control sobre un conjunto de "bienes sociales dominantes", que son: a) bienes monopolizados por un grupo o coalición de grupos; y b) el valor de tales bienes es mantenido por la fuerza y cohesión de quienes se los apropian en exclusiva. El resultado es una clase social dominadora que se ubica en la cima del sistema distributivo; y un conjunto de bienes deseados por muchos, lo que propiciará luchas distributivas o conflictos sociales por el modelo de distribución. 
El establecimiento de empresas trasnacionales depredadoras de recursos naturales propicia el desplazamiento forzado de habitantes de la zona. El neoliberalismo sostiene la idea de que abrir recursos colectivos a la mediación del mercado genera una mayor eficiencia, pero también genera acumulación (Springer, 2015). Al respecto, Guttal (2015) indica que la riqueza es expropiada por actores privados extranjeros y consolidada por las élites nacionales.

Tales actores privados no son únicamente empresas y personas morales, también son actores que operan al margen de la ley, algunos de ellos son grupos paramilitares, cárteles de la droga, grupos criminales y sujetos hiperviolentos. Todos ellos constituyen subjetividades producto de los parámetros capitalistas actuales. En este sentido, Valencia (2017) acuña el término "capitalismo gore" -representa el derramamiento de sangre explícito e injustificado- mediante el cual busca visibilizar la complejidad del entramado criminal mexicano y sus conexiones con el neoliberalismo exacerbado y la globalización. De esta manera es difícil distinguir si este tipo de sujetos actúa al margen de la ley motu proprio o en complicidad con agentes estatales. Estévez (2018) indica que esta connivencia determina un gobierno híbrido, que deviene en la mutación del poder político, en uno que es a la vez criminal y legal, que puede ejercer una violencia extrema y ultra especializada para causar sufrimiento y dolor.

De esta forma, el modelo de acumulación neoliberal permite la impunidad de grupos criminales, así como de pequeñas élites locales y empresas transnacionales, que ejercen su poder cooptando a gobiernos para impulsar reformas jurídicas y despojar el dinero público y los recursos naturales, aumentando la exposición de la población a la corrupción y la violencia.

\section{i) Discurso de odio}

La polarización entre diversos sectores sociales, por las clásicas dicotomías izquierda/derecha, nacionalistas/globalistas, etc. (Molina, 2010); se agudiza con la radicalización del discurso político y denostación del otro, que se asume como enemigo a exterminar. En América Latina los discursos de odio involucran mujeres, pueblos originarios, afrodescendientes, sexualidades disidentes, migrantes, refugiados, extranjeros, creyentes religiosos o a los adversarios políticos. Estos discursos de odio - que llevan implícitas nuevas violencias - inician no solo cuando hay una crisis de sentido nacional o global. Estallan, sobre todo, cuando los derechos de aquellas minorías habían alcanzado ciertos avances en el reconocimiento de sus derechos humanos (CALAS, 2019). Al respecto, António Guterres, Secretario General de Naciones Unidas, ha expresado: 
Reconocemos que el discurso de odio es un ataque a la tolerancia, la inclusión, la diversidad y la esencia misma de nuestras normas y principios de derechos humanos. En términos más generales, ese discurso socava la cohesión social, erosiona los valores comunes y puede sentar las bases de la violencia, haciendo retroceder la causa de la paz, la estabilidad, el desarrollo sostenible y la dignidad humana (Guterres, 2019).

También ha expresado su temor de que el mundo se acerca a otro momento crítico en la lucha contra el "demonio del odio". En América Latina existen experiencias legislativas contra el odio, por ejemplo, en Venezuela con Ley Constitucional contra el Odio, por la Convivencia Pacífica y la Tolerancia, se emitió con la finalidad de reivindicar el derecho del pueblo venezolano al disfrute de la paz como un valor irrenunciable para la efectiva coexistencia. La justificación para la expedición de la ley fue acabar con los mensajes de odio social argumentando que habían sido el disparador de las protestas, entre abril y julio de 2017, contra el gobierno, que culminaron con un saldo de al menos 163 fallecidos (Balbi, 2017). ${ }^{4}$ Ahora bien un discurso de odio se produce, por ejemplo, con el presidente de Brasil Jair Bolsonaro, quien ha pronunciado diversas frases polémicas, entre ellas: "Estoy a favor de la tortura..."; "No emplearía — hombres y mujeres - con el mismo salario"; "Sería incapaz de amar un hijo homosexual [...] prefiero que un hijo mío muera en un accidente a que aparezca con un bigotudo por ahí"; "Yo no soy violador, pero si lo fuera, no la iba a violar porque no lo merece"; "El afrodescendiente más flaco allá pesaba siete arrobas - antigua unidad de medida — . No hacen nada. Creo que ni para procrear sirven más"; "Hay que dar seis horas para que los delincuentes se entreguen, si no, se ametralla el barrio pobre desde el aire"; y "El error de la dictadura fue torturar y no matar" (El top 20 de las frases más polémicas, 2018). Tales expresiones, han provocado que Margarette May Macaulay, Presidenta de la Comisión Interamericana de Derechos Humanos (CIDH), califique esas declaraciones como atrocidades (CIDH "preocupada" por el discurso de odio, 2018).

Estos discursos de animadversión, catalogados por Guterres, como una "retórica cada vez más repugnante", no sólo implican discriminación, xenofobia y racismo, también conllevan otras formas de odio como la misoginia, la homofobia, el desprecio clasista, el macartismo y cualquier forma de exclusión (2019). Ello abona a los procesos de estigmatización y marginalización de los considerados como minorías y grupos vulnerables.

\footnotetext{
${ }^{4}$ Balbi (2017) cree que esta ley de origen es antidemocrática por la Asamblea que la promulgó; mientras que Bracho (2019) considera que era necesaria y sólo falta modificar algunas cuestiones como tipificar expresamente los crímenes de odio.
} 


\section{j) Alienación política y las anatomopolíticas antidemocráticas}

Long (1990) define la alienación política como una respuesta afectiva por parte de un individuo al sistema político y a sus líderes, que es básicamente de naturaleza negativa y que se caracteriza por cuatro sentimientos interrelacionados: 1) sentimiento de ineficacia política; 2) sentimiento de descontento en relación con los resultados del sistema político; 3) sentimiento de desconfianza hacia los motivos y comportamiento de los líderes políticos; y 4) sentimiento de alejamiento del sistema político.

Problemas como fraudes electorales, corrupción, baja participación política, crisis económica, instituciones informales que están dispuestas a promover sus propios intereses por medios ilegales y a veces violentos, así como altas tasas de pobreza, baja calidad de la educación y las deficiencias en el sistema de servicios de salud, etc., demuestran que la democracia en Latinoamérica no está funcionando como fue previsto; lo cual merma la percepción y propicia descontento social hacia ese régimen político. (Rubio \& Kaufman, 2006)

Al lado de tal alienación, las relaciones neoliberales procuran el control y la disciplina de los cuerpos, de las personas. Foucault, citado por Estévez, encontró que el poder disciplinario se centra en los cuerpos individuales, como su objeto, para disciplinarlos y hacerlos dóciles en función de la productividad económica. El uso de las disciplinas del saber y las instituciones por parte del poder disciplinario es lo que Foucault llamó anatomopolítica (Estévez, 2018). Según Dávalos (2009), en muchas pseudo-democracias operan dirigentes que tienen como objetivo disciplinar las luchas, las resistencias y las propuestas alternativas al interior de la democracia liberal. Así, la "democracia disciplinaria" une el poder disciplinario que se ejerce sobre el control de las subjetividades y en la cual las personas se convierten en consumidores o votantes cuyas percepciones sobre la realidad son trabajadas por expertos en mercadeo y publicidad. La democracia disciplinaria se asiste de mecanismos panópticos de control y vigilancia, de ahí la consolidación y la extensión de las formas de criminalización, persecución y violencia social generadas desde el Estado y el partido de gobierno.

El "neoliberalismo disciplinario" se asegura que, a través de una variedad de mecanismos regulatorios, de vigilancia y policiales, las reformas neoliberales sean instituidas, a pesar de lo que la población podría desear. Alternativamente, el poder disciplinario es algo dependiente del discurso circulante, en donde los ideales neoliberales son articulados, internalizados y transmitidos, lo que promueve la racionalidad de poder, es decir, la gubernamentalidad. Visto de esta 
forma, el neoliberalismo conlleva una erosión de control democrático y rendición de cuentas, donde el modelo económico está aislado del escrutinio y las demandas populares. (Springer, 2015)

Bajo las condiciones descritas, el dispositivo antidemocrático es una red de elementos que viola sistemáticamente los derechos humanos, además, permite según Deleuze (1990):

- Visibilizar y analizar cualitativamente la articulación e imbricación de relaciones entre los diversos elementos del dispositivo que atentan contra del régimen democrático: ideas y discursos, procesos de transición, simbología política, actitudes disciplinarias, autoritarias y populistas, concentración de poder, acumulación económica, así como también fenómenos de violencia, impunidad, alienación política y fragilidad institucional.

- $\quad$ Argumentar como la articulación de todos esos elementos descubre un discurso utilitario neoliberal institucional en favor de los intereses de los grupos de poder que predominan. En efecto, en todos estos elementos hay puntos en común tales como discursos e intereses que forman parte de un simulacro, un encubrimiento donde aparentemente se cumple el Estado de Derecho y la democracia, pero no es así, existe la violencia, el enfrentamiento y un discurso de odio que en algunas latitudes se ha radicalizado y que merma la débil democracia en varios países latinoamericanos.

- $\quad$ Señalar las dimensiones de poder que se ejercen mediante agentes públicos y privados o grupos institucionales, paralegales e ilegales, que operan bajo la anuencia del modelo capitalista neoliberal. Como sostiene Honneth (2009), en este dispositivo se advierten los diversos sectores sociales empoderados que participan en el "ejercicio de dominación" y externan su predisposición a validar un sistema desigual de cargas y privilegios. Asimismo, los elementos del dispositivo ayudan a exponer cómo se ejerce la dominación en "regímenes democráticos", contribuyen a pensar cómo se suaviza la opresión en las sociedades contemporáneas y cómo, ese proceso dominación ideológica y discursiva, gana mayor eficacia que sus expresiones físicas más violentas y coercitivas (Abril, 2018).

- $\quad$ Conocer los procesos que afectan la conducta de las personas, físicas y morales, produciendo cierto tipo de subjetividad: víctimas de la violencia extrema, agentes hiperviolentos, empresas transnacionales depredadoras del medio ambiente, actores transnacionales clandestinos, grupos paramilitares, carteles de la droga o migrantes irregulares. 
El andamiaje asentado, justifica el robustecimiento de la democracia. Las dinámicas autoritarias y las lógicas neoliberales deben ser acotadas, en ese sentido, el marco jurídico es una vía para restringir los avances antidemocráticos en América Latina.

\section{REDEMOCRATIZACIÓN Y ESTADO DE DERECHO: ¿CÓMO PUEDE EL DERECHO AYUDAR A SOBREVIVIR A LA DEMOCRACIA?}

Para contestar el interrogante planteado y proponer una serie de acciones a favor de la democracia, en este apartado se considera prima facie el concepto moderno de democracia y de Estado de Derecho. Habermas señala que la concepción de democracia se diferencia de la clásica, en cuanto al tipo de derecho que la rige. El derecho moderno es un derecho positivo, vinculante, que se compone de normas que han sido creadas por el poder legislativo y luego sancionadas por el Estado con el fin de garantizar los derechos subjetivos. Por su parte, el Estado de Derecho o Rule of Law tiene su expresión en la idea de los derechos humanos (Habermas, 2004). Naciones Unidas define al Estado de Derecho como "un principio de gobernanza en el que todas las personas, instituciones y entidades, públicas y privadas, incluido el propio Estado, están sometidas a leyes que se promulgan públicamente, se hacen cumplir por igual y se aplican con independencia, además de ser compatibles con las normas y los principios internacionales de derechos humanos" (Organización de las Naciones Unidas, 2019).

En ese sentido el Estado de Derecho debe servir como una barrera protectora de la democracia en términos de Levistsky (2019). El Estado de Derecho se debe internalizar, los agentes políticos deben comprender y reconocer la legitimidad de los adversarios, su derecho a disentir y no verlos como enemigos. En todos los países de Latinoamérica se reconocen derechos fundamentales que pueden encauzar el sentimiento de polarización u odio: la libertad de expresión y manifestación, libertad de prensa, derechos de asociación, el derecho de participación política, el derecho a un recurso y con ello de acceso a la justicia, debido proceso y la tutela judicial efectiva, el derecho a la reparación del daño, entre otros. Esta debe ser la vía para canalizar todos esos sentimientos y frustraciones.

Para ello el nivel del debate, la narrativa institucional, social y los sectores progresistas, deben coadyuvar divulgando ese bagaje normativo, brindarle expectativas al partido perdedor de que hay esperanza para que acceda al poder, siempre y cuando ellos cuiden y garanticen el marco jurídico que sirve de fundamento para que haya una democracia plena. La democracia funciona, indica 
Levistsky (2019), sólo cuando los partidos políticos saben perder, aceptar la derrota, es decir, deben existir dos condiciones: 1) el partido perdedor debe creer que puede ganar en el futuro y 2) que la pérdida no traiga consecuencias apocalípticas y no sea una catástrofe. De lo contrario, los partidos hacen uso lo que sea y se aferran al poder hoy, y la desesperación los induce a jugar sucio. En este supuesto el discurso a favor del Estado de Derecho debe oponerse y sancionar a los partidos desleales al régimen democrático, a las oposiciones conspirativas y golpistas que inciten a la desestabilización y a acciones radicales frente al gobierno. Los parámetros del Estado de Derecho al internalizarse pueden revelar las verdaderas intenciones antidemocráticas y la falta de responsabilidad política de la oposición.

Bajo el Estado de Derecho, también es menester que los mandatarios, jefes de Estado o presidentes, se auto-contengan, no ejerciendo un derecho legal que conlleve el acaparamiento de funciones, la arbitrariedad o repercusiones políticas que convulsionen la gobernabilidad. Al despolitizar y moderarse proveerán las condiciones necesarias para disminuir el nivel de conflicto político-social. Se trata de evitar que la interpretación de un precepto pueda ser tal que implique violar el espíritu constitucional a través de la propia letra de la Constitución.

Por otra parte, para contrarrestar el dispositivo antidemocrático descrito en el apartado anterior, cuyos elementos heterogéneos son amenazas letales a las democracias latinoamericanas, se tienen que construir acciones que prescriban el papel del Estado de Derecho en la transformación social que se presenta en la región. Esta propuesta debe ir de acuerdo con el discurso jurídico que se profundice en la práctica de los operadores jurídicos y sujete a los ciudadanos a cumplir la ley con base en su funcionalidad, utilidad y coercibilidad.

\section{El Estado de Derecho en las nomósferas y las heterotopías}

Los mecanismos arbitrarios utilizados como elementos del dispositivo antidemocrático rebasan lo sancionado por los marcos jurídicos nacionales e internacionales. Sin embargo, el derecho como parámetro común deontológico y axiológico debe prever una herramienta contra los que constantemente pretenden interpretarlo y aplicarlo a favor de intereses ajenos a la democracia.

El discurso jurídico es poder (Vásquez Rocca, 2012). Al respecto, Van Dijk (2004) sostiene: "controlando al menos una parte del discurso público, las elites de poder son capaces de controlar, al menos, una parte de las mentes de algunas personas". Para lograr que el derecho no sea cooptado con esos grupos 
de poder fáctico, el derecho debe ser concebido desde un espectro más amplio. Es ahí donde el concepto de heterotopía como un espacio heterogéneo de lugares y relaciones sería de vital importancia para el análisis jurídico a la hora de definir, no sólo la red global que caracteriza el territorio tardo-capitalista, sino la propias ciudades, comunidades y espacios normativos contemporáneos (Centro Andaluz de Arte Contemporáneo, 2020). En este sentido, A. Vásquez Rocca indica: "Los hombres, nos recuerda Sloterdijk, vivimos en espacios, en esferas, en atmósferas" (2008). Este problema se sitúa en lo que se denomina gubernamentalidad cuya característica más decisiva consiste en la distribución — la oikonomia - de las personas. En ese sentido L. Vásquez Rocca (2012) argumenta que poblaciones enteras de desplazados, de refugiados, de consumidores, de marginales, abren un espacio en otro en el seno de las propias urbes, quedan al margen del desarrollo, del Estado de bienestar, pero también al margen de la protección jurídica. Así quedan a la deriva las nuevas heterotopias que distribuye la gubernamentalidad global; la polis occidental es llevada a su definitiva implosión.

Si bien es cierto que generalmente se toma como parámetro geográfico analítico los países y la región latinoamericana, es imprescindible acotar que existen áreas geográficas que no son uniformes; en otras palabras, existen en términos de Agnew (1995) "geografías ocultas", zonas "no convencionales" o invisibles para el derecho y la política que podríamos llamar escalas geográficas: zonas fronterizas, "cuarto mundo", lugares de conflicto, etc. Al respecto, Delaney y Leitner (1997), sostienen que la noción geográfica, no problemática, predefinida y fija de los espacios delimitados - de diferentes tamaños o niveles de gobernanza como el local, regional, nacional y global — ha sido desafiada.

De esta forma se pueden imaginar y comprender distintas escalas, ergo, la construcción política de la escala económica - T-MEC, desregulación, escalas flexibles de abastecimiento y comercialización- (Delaney \& Leitneh, 1997). Pero también es aplicable, por ejemplo, a las zonas fronterizas, a los lugares de influencia de empresas de mega-minería, a las zonas donde hay una importante presencia paramilitar o de cárteles de la droga, las cuales quedan excluidas de la práctica del "modelo ortodoxo del derecho". Esta visión estandarizada del derecho vinculada a la dogmática jurídica que tiene a su vez su fundamento en el positivismo jurídico, no permite abarcar estos espacios donde predomina un limbo jurídico o espacios de excepción, y que es imperioso regular a través del Estado de Derecho.

Desde la perspectiva de la geografía crítica legal Delaney y Leitner (1997) aportan el término de nomósferas que define el conjunto de mundos 
culturales y materiales que se constituyen por la materialidad de las relaciones legales y las representaciones discursivas de relaciones socio-espaciales del derecho. El término supera la estrecha visión del derecho limitada a la promulgación de la ley. Estos autores incluyen en la nomósfera a lo normativo inflexionado, como las reglas con las cuales se constituye el mundo, que pueden ser tácitas o explícitas, informales o formales, legales o ilegales. En el marco de lo nómico, se pueden estudiar tanto las prácticas que se consideran legales como las ilegales, pues para el autor, tanto lo legal como lo ilegal tienen atributos de nomicidad (Delaney \& Leitner, 1997). Lo nómico incluye las reglas no formalizadas que gobiernan la relación en las instituciones públicas y privadas, así como las regulaciones institucionales que gobiernan espacios como el hogar, que desde una mirada positivista de lo legal, se identificarían como extralegales o alegales.

Algunos elementos para su análisis son contextos, actores, estrategias, maniobras, apuestas, ideologías y plazos que deberían ser parte de un proceso más completo comprensión y que pueden ayudar a solucionar algunos problemas antidemocráticos. Es ahí donde los intérpretes y operadores jurídicos deben pensar el derecho de una manera diferente, incluyente, disgregar la identificación marco jurídico estatal y derecho, para concebirlo más allá de eso. Las nomósferas permiten concebir el derecho como algo más que normas jurídicas y, por ende, el Estado de Derecho puede irradiar y extenderse hacia esas geografias ocultas que han permanecido arbitrariamente en el limbo jurídico. Permite abarcar de manera integral fenómenos y prácticas que han quedado aisladas de la configuración y operación del derecho; brindarles prevención, vigilancia y reparación.

\section{EI Estado de Derecho e igualdad jurídica compleja}

Bien lo indica Torres (2008), el respeto a los principios fundamentales de igualdad, no discriminación y los derechos humanos son las piedras angulares de los sistemas de derecho y de la cultura de la legalidad. Constituyen la base para el desarrollo de una sociedad democrática y la vigencia de un Estado de Derecho. En estos términos, Walzer (2004) considera que el problema actual más importante para la democracia y la justicia es atender los reclamos del igualitarismo político, abolicionista y emancipador, frente al problema de la dominación y los privilegios aristocráticos, burocráticos, étnicos, sexuales, o bien asociados con el predominio del dinero. Para este autor, una sociedad que adopte el principio de la igualdad total sería un mundo hipócrita de falsas apariencias, con individuos obligados a verse y actuar igual y tener lo mismo, vigilados por una élite que 
simularía en realidad no existir. Por ello tiene más sentido hablar de un régimen de igualdad compleja o de dominación atenuada, en el cual el dominio en una esfera o área de interacción humana no pueda conferir ventajas significativas en otras esferas.

La clave para el desarrollo de un régimen de igualdad compleja o de dominación atenuada, de acuerdo con Walzer (2004), reside en el siguiente principio: Ningún bien social " $\mathrm{X}$ " ha de ser distribuido entre hombres y mujeres que poseen algún bien social " $\mathrm{Y}$ ", simplemente porque poseen "Y", y sin tomar en cuenta el significado de "X". En este sentido, Baxi (2010) indica que es posible lograr esta igualdad compleja y pone de ejemplo la propia Constitución de la India, que con el liderazgo adjudicativo que goza busca hacer que las ideas sobre igualdad ante la ley sean compatibles con la igualdad de oportunidades de acceso y resultado para todos.

En este rubro hay avances parecidos en América Latina. Moura de Oliveira y Veríssimo Veronese (2019) indican que, a partir del proceso de democratización, los países latinoamericanos comenzaron a incorporar cuotas para negros e indígenas en las instituciones de enseñanza superior que, progresivamente, fueron ampliados a favor de grupos sociales estigmatizados. Otro ejemplo paradigmático es el defendido y sustentado por los Estudios de Género, los cuales, ante el marco cultural y de valores que subestima las capacidades y el desempeño de las mujeres, han incorporado las denominadas "acciones afirmativas" 5 a favor de las mujeres con el objetivo lograr, grosso modo: igualdad de oportunidades, igualdad de acceso a esas oportunidades e igualdad de resultados (Torres, 2008). Al respecto, el artículo $4^{\circ}$ de la Convención sobre la Eliminación de todas las Formas de Discriminación contra la Mujer (Convención CEDAW), dispone la adopción de medidas especiales de acciones afirmativas en los siguientes términos: "La adopción por los Estados Partes de medidas especiales de carácter temporal encaminadas a acelerar la igualdad de facto entre el hombre y la mujer[...] estas medidas cesarán cuando se hayan alcanzado los objetivos de igualdad de oportunidad y trato" (Convención sobre la Eliminación de todas las Formas de Discriminación contra la Mujer, 1979).

Estas acciones equitativas han impactado favorablemente a las mujeres, ello ha propiciado que se extiendan hacia otros grupos sociales, étnicos, minoritarios o que históricamente han sufrido discriminación a causa de injusticias

\footnotetext{
${ }^{5}$ También conocidas como "políticas de diferenciación para la igualdad", "medidas especiales temporales", "discriminación positiva" o "discriminación inversa" (Comisión Interamericana de Derechos Humanos, 1999).
} 
sociales, suscribiéndoles un trato preferencial en el acceso o distribución de ciertos recursos o servicios, con el objetivo de mejorar su calidad de vida y compensarlos por los perjuicios o la discriminación de la que han sido víctimas. De ahí que esta idea de igualdad compleja debe irradiarse a todos los sistemas jurídicos latinoamericanos en donde las asimetrías sociales y económicas son cada vez más profundas. La aplicación de estas acciones es fundamental para lograr la igualdad sustantiva de derechos, por ello importante defenderlas frente a las corrientes que manifiestan que estas gestiones ubican a sus destinatarios en circunstancia de inferioridad con respecto a las demás personas. (Organización de los Estados Americanos, 2010)

\section{Identificación de la democracia con el Estado Constitucional de Derecho}

La democracia es un régimen amplio que no se limita al ejercicio de los derechos políticos y la calidad de las elecciones; es un régimen que requiere del contenido axiológico que prescribe el Estado Constitucional de Derecho. Este Estado reconoce derechos sustantivos previstos en la Constitución de suma importancia denominados derechos fundamentales, así la norma suprema del Estado restringe los actos arbitrarios de las autoridades, en ella se establecen los cimientos para la organización del Derecho público de una nación y constituye "el verdadero fundamento de las otras leyes" (Lasalle, 1999). Dice Baxi, la Constitución es "el marco normativo y aspiracional que enuncia el orden social deseado" (2010).

De tal manera, la democracia debe relacionarse fundamentalmente con el Estado constitucional. No debe permitirse que el término quede sesgado por diversos grupos y poderes políticos autoritarios en turno que puedan asignarle la connotación que sea redituable a sus intereses y que sirva para legitimar leyes, actitudes y políticas particulares. Sin embargo, actualmente es común encontrar términos y tipologías como: democracia mayoritaria, democracia consensual, democracias presidencial, democracia parlamentarias, democracia delegativa, democracia representativa, democracia republicana, democracia liberal y democracia marxista, democracia clásica, democracia protectora, democracia desarrollista, democracia directa, democracia elitista, democracia pluralista, democracia legal, democracia participativa, democracia procedimental, democracia resultadista, democracia minimalista, democracia maximalista, etc. (Barruet \& Navia, 2013), que permiten inferir que a la democracia es "todo"; todo le cabe, todo le 
es afín y la justifica, en otras palabras, es omnicomprensiva. No obstante, en cada uno de esos términos existe una carga ideológica implícita en detrimento de lo que no abarca, de lo que no está previsto.

Además, el Estado constitucional necesita de jueces conscientes de las problemáticas sociales, que puedan tener un amplio criterio y manejen enfoques inclusivos. Insiste Baxi, que quizás sería bueno explorar ideas como la demosprudencia, un término emergente en la teoría constitucional de los Estados Unidos, esta rúbrica toma muy en serio la "relación dialógica entre los tribunales y las personas" (2010). Guinier y Torres acuñaron el término demosprudencia para definir prácticas legales que se refieren específicamente a los movimientos sociales e intentan catalizar el cambio legal, incluido el constitucional. Baxi asegura que esta idea es posible y que mejora la vida bajo una democracia constitucional, pone de ejemplo al juez Krishna Iyer. La demosprudencia se refiere a la forma en que la Corte interpreta la jurisprudencia existente y responde a la comprensión constitucional representada por actores de no élite en los movimientos sociales (Guinier \& Torres, 2014).

En consecuencia, el Estado Constitucional de Derecho puede ayudar a la democracia a garantizar los derechos humanos y continuar legitimando su existencia. Es evidente que los valores prescritos por este Estado y las propuestas de las repúblicas democráticas reclaman: "la necesidad de re-establecer el lazo social éticamente mediado, sustantivamente cargado de valores moralmente vinculantes capaces de amortiguar los embates economicistas, instrumentales, y alienantes" (Fleitas González, 2014, p. 5).

\section{CONCLUSIONES}

La crisis letal de la democracia en América Latina ha sido el centro del debate político contemporáneo. La transición hacia la democracia nunca llegó a consolidarse en toda América Latina. Las promesas democráticas hechas por líderes políticos no han sido cumplidas cabalmente en la región, poniendo en entredicho su futuro en la zona. Actualmente, muchos agentes, grupos y sectores, privados y públicos, legales e ilegales, provocan fenómenos de características complejas e híbridas y asumen posturas que causan escenarios distópicos en donde tales poderes fácticos se empoderan conculcando los derechos humanos y fracturando el sistema democrático. En esta investigación se pudo observar que en algunas latitudes latinoamericanas no existe el monopolio de la fuerza estatal. 
El dispositivo antidemocrático permitió detectar y externalizar los vínculos y las cuestiones subrepticias entre redes de elementos que ocultan o justifican prácticas antidemocráticas. Al aplicar categorías de análisis del pensamiento crítico se revelaron condiciones estructurales que subyacen en algunos países latinoamericanos. Tales sinergias ocultas se pudieron examinar a la luz de nociones que procuran el fortalecimiento democrático; por consiguiente, el análisis crítico tuvo un efecto utilitario permitiendo conocer las diferentes formas de cómo están muriendo las democracias en América Latina y proponer acciones para su redemocratización.

El derecho como construcción humana tiene la función de dar certeza y seguridad jurídica a todas las relaciones individuales y sociales susceptibles de protección, pero también su marco regulador debe aplicarse también a zonas invisibles para el derecho, propiciando la igualdad entre sus habitantes, grupos y sectores de acuerdo a lo establecido en la Ley Suprema. Así, la propuesta descrita en el último apartado esquematiza brevemente algunas posibles acciones para contrarrestar el dispositivo antidemocrático. Se enfatiza la importancia del Estado de Derecho para garantizar los derechos humanos y frenar el proceso deletéreo que sufre la democracia en la región.

Una democracia que aspire a garantizar los derechos humanos debe enfrentar las nuevas vicisitudes siempre ponderando su vocación humanista. La democracia y el Estado de Derecho constituyen un binomio que debe reconfigurarse paulatinamente, ya que ambos requieren mantenimiento, pues no operan de facto y necesitan de la participación social y política, pero también la intervención normativa para reajustarlas a los desafíos contemporáneos.

\section{REFERENCIAS}

Abril, F. (2018). Repensar la dominación: Axel Honneth y el legado de la Teoría Crítica. Revista Mexicana de Ciencias Politicas y Sociales, 63(232), 103-128. https://doi.org/10.22201/fcpys.2448492xe.2018.232.58154

Agamben, G. (2009). What Is an Apparatus? and Other Essays. Stanford University Press.

Agnew, J. (1995). The Hidden Geographies of Social-Science and The Myth of The Geographical Turn. Environment and Planning D: Society and Space, 13(4), 379-380. https://doi.org/10.1068/d130379

Akerman M., Trousdell, M. C., \& Lacabo P. (2020). Las amenazas al Sistema Único de Salud en el Brasil: ¡Una agenda de resistencia es necesaria! (2016-2020). Revista Estado y Políticas Públicas, (14), 93-106.

Aliaga, J. (2020, 21 de enero). El gobierno interino de Bolivia declara el fin al "culto a la personalidad" y borra los símbolos de Evo Morales. Noticias Univisión. 
https://www.univision.com/noticias/america-latina/el-gobierno-interino-de-bolivia-declara-el-fin-al-culto-a-la-personalidad-y-borra-los-simbolos-de-evo-morales

Allub, L. (1980). El colapso de la democracia liberal y los orígenes del fascismo colonial en Argentina. Revista Mexicana de Sociología, 42(3), 1105-1144. https://doi.org/10.2307/3539996

Altamirano Dimas, G. (2017). Derechos humanos de cuarta generación: Un acercamiento. Centro de Estudios Sociales y de Opinión Pública (CESOP); Cámara de Diputados, XLIII Legislatura.

Altmann, J. (2018, 15 de octubre). La OCDE ve a la corrupción como un desafío para los gobiernos latinoamericanos. Télam Latinoamérica. https://www.telam.com.ar/notas/201810/298377-la-ocde-ve-a-la-corrupcion-como-un-desafio-para-los-gobiernoslatinoamericanos.html

Balbi M. (2017, 20 de noviembre). La ley contra el odio busca acabar con los vestigios de democracia en Venezuela. The New York Times. https://www.nytimes.com/es/2017/11/20/espanol/opinion/la-ley-contra-el-odio-busca-acabar-con-los-vestigios-de-democracia-envenezuela.htm

Banco Mundial. (s.f.). Índice de Gini. https://datos.bancomundial.org/indicador/SI.POV.GINI?view=map

Barruet, F., \& Navia, P. (2013). Tipologías de democracia representativa en América Latina. Política y Gobierno, 20(2), 265-307.

Baxi, U. (2010). The judiciary as a resource for Indian democracy. India Seminar. https://www.india-seminar.com/2010/615/615_upendra_baxi.htm

Bonometti, P. y Ruiz, S. (2010). La democracia en América Latina y la constante amenaza de la desigualdad. Andamios, 7(13), 11-36. https://doi.org/10.29092/uacm.v7i13.116

Bracho, A. C. (2019, 28 de marzo). Juzgar la ley: La urgente reforma de la Ley contra el Odio, por la Convivencia Pacífica y la Tolerancia. ALAI, América Latina en Movimiento. https://www.alainet.org/es/articulo/199011

Brown, J. (2018). El colapso de la democracia en México. Bien Común, (279), 5-23.

CALAS. (2019). Plataformas para el Diálogo: "Nuevos discursos de odio y sus contradiscursos en América Latina". CALAS, Centro Universitario de Ciencias Sociales y Humanidades. http://www.calas.lat/es/convocatorias/plataformas-para-el-di\%C3\%A1logo-nuevos-discursos-de-odio-y-sus-contradiscursos-en-am\%C3\%A9rica

Castro, E. (2004). El vocabulario de Michel Foucault. Un recorrido alfabético por sus temas, conceptos y autores. Universidad Nacional de Quilmes.

Cebotarev, E. A. (2003). El enfoque Crítico: Una revisión de su historia, naturaleza y algunas aplicaciones. Revista Latinoamericana de Ciencias Sociales, Niñez y Juventud, (1), 1-27.

Centro Andaluz de Arte Contemporáneo. (2020). Glosario: Heterotopía. Atributos Urbanos. https://www.atributosurbanos.es/terminos/heterotopia/

CEPAL. (2017). Pese a avances recientes, América Latina sigue siendo la región más desigual del mundo. https://www.cepal.org/es/comunicados/cepal-pese-avances-recientes-america-latina-sigue-siendo-la-region-mas-desigual-mundo

Cibrian, R. (1978). Violencia política y crisis democrática: España en 1936. Revista de Estudios Políticos, (6), 81-115. 
CIDH "preocupada" por el discurso de odio de Jair Bolsonaro. (2018, 12 de noviembre). La Nación. https://www.nacion.com/el-mundo/politica/cidh-preocupada-por-el-discurso-deodio-de/V6UX7GEHINBCJCCJ6OMDBRKVK4/story/

Comisión Interamericana de Derechos Humanos. (1999). Consideraciones sobre la compatibilidad de las medidas de acción afirmativa concebidas para promover la participación política de la mujer con los principios de igualdad y no discriminación. https://www.cidh.oas.org/annualrep/99span/capitulo6a.htm

Convención sobre la Eliminación de Todas las Formas de Discriminación contra la Mujer (CEDAW), Organización de la Naciones Unidas (ONU), 1979.

https://www.oas.org/dil/esp/Convencion_sobre_todas_las_formas_de_Discriminacion_contra_la_Mujer.pdf

Corrales, J. (2019, 18 de noviembre). Tristes lecciones desde Bolivia. The New York Times. https://www.nytimes.com/es/2019/11/18/espanol/opinion/tristes-lecciones-desde-bolivia.html

Cristi, R., \& Tranjan, J. R. (2010). Taylor Charles y la democracia republicana. Revista de Ciencia Política, 30(3), 599-617. https://doi.org/10.4067/S0718-090X2010000300002

Cruz Olmeda, J. (2019). ¿Por qué ganó Bolsonaro en Brasil? Revista Mexicana de Sociología, $81(3), 665-674$.

Dalby, C., \& Carranza, C. (2019). Balance de InSight Crime sobre los homicidios en 2018. InSight Crime, Investigación y Análisis de Crimen Organizado. https://es.insightcrime.org/noticias/analisis/balance-de-insight-crime-sobre-los-homicidios-en2018/

Dávalos, P. (2009, 9 de marzo). La democracia disciplinaria. América Latina en Movimiento. https://www.alainet.org/es/active/29347

De la Torre, C. (2019, 14 de octubre). ¿El fin de la Perestroika de Lenín Moreno en Ecuador? Letras Libres. https://www.letraslibres.com/mexico/politica/el-fin-la-perestroika-leninmoreno-en-ecuador

Degregori, C. I., \& Rivera Paz, C. (1993). Perú 1980-1993: Fuerzas armadas, subversión y democracia. Redefinición del papel militar en un contexto de violencia subversiva y colapso de régimen democrático. Instituto de Estudios Peruanos, Documento de Trabajo, (53). http://repositorio.iep.org.pe/bitstream/IEP/906/2/Documentodetrabajo53.pdf

Delaney, D., \& Leitner, H. (1997). The political construction of scale. Political Geography, 16(2), 93-97. https://doi.org/10.1016/S0962-6298(96)00045-5

Deleuze, G. (1990). Michel Foucault, filósofo. Gedisa.

El top 20 de las frases más polémicas de Jair Bolsonaro. (2018, 28 de octubre). Perfil. https://www.perfil.com/noticias/internacional/frases-mas-polemicas-de-jair-bolsonaro.phtml

Estévez, A. (2018). Biopolítica y necropolítica: ¿Constitutivos u opuestos?, Espiral, Estudios sobre Estado y Sociedad, 25(73), 9-43. https://doi.org/10.32870/espiral.v25i73.7017

Fleitas González, M. (2014). ¿Es la apatía cívica una patología social? XIII Jornadas de Investigación de la Facultad de Ciencias Sociales, Montevideo, septiembre de 2014.

Foucault M. (1983). El Discurso del poder. Folios.

Foucault, M. (1998). Historia de la sexualidad: La voluntad de saber. Siglo Veintiuno. 
Fraser, N. (2012, 23 de noviembre). Capitalism, crisis, critique - ein Workshop [Taller de trabajo]. Universidad Humboldt de Berlín.

Galindo, J. (2019), Por qué los latinoamericanos se desencantan con la democracia. El País. https://elpais.com/internacional/2019/08/01/america/1564676652_297133.html

Gobierno autoritario y sin respuestas reales. (2019, 23 de octubre). El Siglo. https://www.elsiglo.cl/2019/10/23/gobierno-autoritario-y-sin-respuestas-reales/

Guinier L., \& Torres, G. (2014). Changing the wind: Notes toward a demosprudence of law and social movements. The Yale Law Journal, 8(123), 2740-2804.

Guterres, A. (2019, 18 de junio). El discurso del odio, incendio arrasador. Secretaria General de las Naciones Unidas. https://www.un.org/sg/es/content/sg/articles/2019-06-18/thewildfire-of-hate-speech

Guti, J. A. (2016, 16 de septiembre). Venezuela: Maduro amplía por cuarta vez el arbitrario e inútil decreto de emergencia económica. Hispanidad. https://www.hispanidad.com/hemeroteca/confidencial/venezuela-maduro-amplia-por-cuarta-vez-el-arbitrario-e-inutildecreto-de-emergencia-economica_255479_102.html

Guttal, S. (2005). A suitable boy: Paul Wolfowitz and the World Bank. América Latina en Movimiento. https://www.alainet.org/es/node/113103

Gwangeun, C. (2016). Measuring democratic performance: A multidimensional approach. University of Essex.

Habermas, J. (2004). El Estado democrático de Derecho: ¿Una unión paradójica de principios contradictorios? https://revistas.ucm.es/index.php/ANDH/article/download/ANDH0101110435A/21009

Hawkins, K. A., Carlin, R. E., Littvay, L., \& Rovira Kaltwasser, C. (eds.). (2019). The ideational approach to populism: Concept, theory, and análisis. Routledge. https://doi.org/10.4324/9781315196923

Honneth, A. (2009). Crítica del poder. Mínimo Tránsito.

ICTJ. (s.f.). ¿Qué es la justicia transicional? ICTJ, Justicia, Verdad y Dignidad. https://www.ictj.org/es/que-es-la-justicia-transicional

Innerarity, D. (2011, 23 de julio). Una tensión democrática. El Diario Vasco. https://www.diariovasco.com/v/20110723/opinion/articulos-opinion/tension-democratica-20110723.html

Jalife, A. (2019). Culiacán fue una trampa para derrocar al Presidente López Obrador [Vídeo]. YouTube. https://youtu.be/zM2HAj53iTg

Lasalle, F. (1999) ¿Qué es una Constitución? http://datateca.unad.edu.co/contenidos/90150/Curso_AVA/Curso_AVA_8-02/Entorno_de_Conocimiento_8-02/Bibliografia_Unidad_1/LaSalle_Ferdinand_Que_es_una_Constitucion.pdf

Le Clercq, J. A., Cháidez, A., \& Rodríguez, G. (2016). Midiendo la impunidad en América Latina: Retos conceptuales y metodológicos. Iconos Revista de Ciencias Sociales, (55), 69-91. http://dx.doi.org/10.17141/iconos.55.2016.1934

Le Clercq, J. A., \& Rodríguez Sánchez Lara, G. (coord.). (2017). Índice Global de Impunidad (IGI), 2017: Dimensiones de la Impunidad Global. Fundación Universidad de las Américas. https://www.udlap.mx/cesij/files/indices-globales/5-IGI_2017_ESP-UDLAP.pdf 
Levistsky, S. (2019, 28 de noviembre). ¿Cómo mueren las democracias? [Conferencia magistral]. Colegio de México, Ciudad de México.

Ley Constitucional contra el Odio, por la Convivencia Pacífica y la Tolerancia, Gaceta Oficial 41.274 del 8 de noviembre de 2017, Venezuela, Asamblea Nacional Constituyente.

Leznova, N. G. (2020). La extraña política de Jair Bolsonaro y la COVID-19. Revista Política Internacional, (7), 33-42.

Linz, J. J. (1996). La quiebra de las democracias. Alianza Universidad.

Long, S. (1990). Explicando la Alienación Política. Psicología Política, (1), 87-107. https://www.uv.es/garzon/psicologia\%20politica/N1-4.pdf

Malloch Brown, M. (2004). La Democracia en América Latina: Hacia una democracia de ciudadanas y ciudadanos. Alfaguara.

Márquez S. (2019, 7 de febrero). Populismo y Democracia. El Universal. https://www.eluniversal.com.mx/columna/solange-marquez/nacion/populismo-y-democracia

Martínez Espinoza, M. I. (2015). Reconocimiento sin implementación: Un balance sobre los derechos de los pueblos indígenas en América Latina. Revista Mexicana de Ciencias Politicas y Sociales, 60(224), 251-277. https://doi.org/10.1016/S0185-1918(15)30010-6

Martínez Vara, G. (2019, 4 de agosto). Democracia en América Latina. La Llave de Pandora. https://lallavedepandora.com/2019-panorama-de-la-democracia-en-america-latina/

Melguizo, A. (2018, 15 de octubre). La OCDE ve a la corrupción como un desafío para los gobiernos latinoamericanos. Télam Latinoamérica. https://www.telam.com.ar/notas/201810/298377-la-ocde-ve-a-la-corrupcion-como-un-desafio-para-los-gobiernoslatinoamericanos.html

Mizrahi, D. (2019, 17 de marzo). El ranking que muestra quiénes son los líderes más populistas de los últimos 20 años. INFOBAE. https://www.infobae.com/ame$\mathrm{rica} / \mathrm{mundo} / 2019 / 03 / 17 /$ el-ranking-que-muestra-quienes-son-los-lideres-mas-populistas-de-los-ultimos-20-anos/

Molina F. (2010). Democracia Arbitraria. Ediciones Pazos Kanki. https://www.bivica.org/files/democracia-arbitraria.pdf

Moss, R. (1977). El colapso de la democracia. Cosmos.

Moura de Oliveira G., \& Veríssimo Veronese, M. (2019). Brasil y el "fenómeno Bolsonaro": Un análisis preliminar, Revista Mexicana de Ciencias Politicas y Sociales, 64(237), 245268. https://doi.org/10.22201/fcpys.2448492xe.2019.237.68273

Nueve de cada 10 homicidios dolosos en 2018 quedaron impunes en el país. (2019, 3 de diciembre). INFOBAE. https://www.infobae.com/america/mexico/2019/12/04/nueve-de-cada10-homicidios-dolosos-en-2018-quedaron-impunes-en-el-pais/

Observatorio de Igualdad de Género de América Latina y el Caribe. (2019). Feminicidio. https://oig.cepal.org/es/indicadores/feminicidio

Oppenheimer, A. (2003, 11 de marzo). La amenaza de las áreas sin ley. La Nación. https://www.lanacion.com.ar/el-mundo/la-amenaza-de-las-areas-sin-ley-nid479940

Organización de las Naciones Unidas. (2019). ¿Qué es el Estado de Derecho? La ONU y el Estado de Derecho. https://www.un.org/ruleoflaw/es/what-is-the-rule-of-law/ Ortiz, V. (2018, 28 de diciembre). Populismo y democracia. El Heraldo de México. 
Pettiná, V., \& Rojas, R. (2020). Las encrucijadas de América Latina, El País, 14 de enero. https://elpais.com/elpais/2020/01/14/opinion/1578962891_302622.html

Pirotta, I. L. (2019). El autoritarismo de Jair Bolsonaro y las consecuencias de su política ambiental, Perfil, viernes 23 agosto, https://www.perfil.com/noticias/opinion/opinion-ignacio-lautaro-pirotta-el-autoritarismo-de-jair-bolsonaro-y-las-consecuencias-de-su-politica-ambiental.phtml

Por qué tantos manifestantes alrededor del mundo están sufriendo lesiones en los ojos. (2019, 27 de noviembre). BBC News Mundo. https://www.bbc.com/mundo/noticias-internacional50511744

Puerta Riera, M. I. (2016) Crisis de la democracia: Un recorrido por el debate en la teoría política contemporánea, Espiral, Estudios sobre Estado y Sociedad, 23(65), 9-43. https://doi.org/10.32870/espiral.v23i65.4454

Rivas Molina, F. (2018, 9 de noviembre). El Latinobarómetro registra en 2018 el "annus horribilis" de las democracias de América Latina. El País. https://elpais.com/internacional/2018/11/09/america/1541766116_145827.html

Roca Jusmet, L. (2016). Slavoj Žižek sobre el goce en la moral y en la política. Differenz. Revista internacional de estudios heideggerianos y sus derivas contemporáneas, 2(3), 255262. https://doi.org/10.12795/Differenz.2016.i02.15

Rubio, L., \& Kaufman, S. (coord.). (2006). México: Democracia ineficaz. Cámara de Diputados, LIX Legislatura; Porrúa; CIDAC.

Springer, S. (2015). Sic transit gloria mundi: There's something rotten in the state of Cambodia. Violent neoliberalism: Development, discourse and dispossession in Cambodia. Palgrave Macmillan. https://doi.org/10.1057/9781137485335_1

Sputnik. (2021, 17 de mayo). Iván Duque despliega fuerza pública para eliminar bloqueos. $L a$ Jornada. https://www.jornada.com.mx/notas/2021/05/17/mundo/ivan-duque-despliegafuerza-publica-para-eliminar-bloqueos/

Organización de los Estados Americanos. (2010). Taller de Expertos/as de la Temática Afrodescendiente en las Américas. http://www.oas.org/dil/esp/publicacionoficial_tallerdeafrodescendiente.pdf

Taylor, C. (2019, 17-19 de junio). Benjamin-Lectures: Democracy and its crises [Conferencia]. Universidad Humboldt de Berlín.

Torres, I. (2008). Derechos políticos de las mujeres, acciones afirmativas y paridad. Revista IIDH, (47), 225-240.

Transparency International. (2019). Barómetro Global de la Corrupción, América Latina y el Caribe 2019: Opiniones y experiencias de los ciudadanos en materia de corrupción. https://www.transparency.org/files/content/pages/2019_GCB_LAC_Full_Report_ES.pdf

Uprymny Yepes, R. (2020, 7 de septiembre). Un Duque que quiere reinar. Dejusticia.

Urbinati, N. (2014). Democracy disfigured: Opinion, truth, and the people. Harvard University Press. https://doi.org/10.4159/harvard.9780674726383

Valencia, S. (2017). Necropolítica y capitalismo gore [Conferencia]. Seminario dedicado a Los derechos humanos en el capitalismo contemporáneo como teoría y práxis, Facultad Latinoamericana de Ciencias Sociales (FLACSO). 
Van Dijk, T. A., (2004). Discurso y dominación. Grandes Conferencias en la Facultad de Ciencias Humanas, Universidad Nacional de Colombia, Bogotá.

Vásquez Rocca, A. (2008). Peter Sloterdijk: Esferas, helada cósmica y políticas de climatización. Edicions Alfons el Magnànim.

Vásquez Rocca, L. (2012). Microfísica del poder y biopolítica en Foucault: Posibles correspondencias con las antropotecnias y heterotopías en la Hiperpolítica sloterdijkdiana. Eikasia, (46), 163-178.

Walzer, M. (2004). Las esferas de la justicia, una defensa del pluralismo y la igualdad. FCE.

Woldenberg, J. (2018). Vida y muerte de la democracia, John Keane: La siempre pertinente y frágil democracia. Revista de la Universidad de México, (840), 148-155.

Wolin, S. (2004). Politics and vision: Continuity and innovation in Western political thought. Princeton University Press. https://doi.org/10.1515/9781400883530 